\title{
A simple ergonomic measure reduces fluoroscopy time during ERCP: A multivariate analysis
}

\section{(9)( $\circledast \Theta$}

\author{
Authors \\ Fahd Jowhari ${ }^{1}$, Wilma M. Hopman², Lawrence Hookey \\ Institutions \\ 1 Gastrointestinal Diseases Research Unit, Kingston General \\ Hospital, Queen's University, Kingston, Ontario, Canada \\ 2 Clinical Research Centre, Kingston General Hospital, and \\ Department of Public Health Sciences, Queen's University, \\ Kingston, Ontario, Canada
}

submitted 20.1.2016

accepted after revision $\quad 30.12 .2016$

Bibliography

DOI http://dx.doi.org/10.1055/s-0043-102934 |

Endoscopy International Open 2017; 05: E172-E178

(c) Georg Thieme Verlag KG Stuttgart · New York

ISSN 0013-726X

Corresponding author

Lawrence Hookey, MD, FRCPC, Division of Gastroenterology, Hotel Dieu Hospital, 166 Brock Street, Kingston, ON K7L 5G2 hookeyl@hdh.kari.net

\section{ABSTRACT}

Background and study aims Endoscopic retrograde cholangiopancreatgraphy (ERCP) carries a radiation risk to patients undergoing the procedure and the team performing it. Fluoroscopy time (FT) has been shown to have a linear relationship with radiation ex- posure during ERCP. Recent modifications to our ERCP suite design were felt to impact fluoroscopy time and ergonomics. This multivariate analysis was therefore undertaken to investigate these effects, and to identify and validate various clinical, procedural and ergonomic factors influencing the total fluoroscopy time during ERCP. This would better assist clinicians with predicting prolonged fluoroscopic durations and to undertake relevant precautions accordingly.

Patients and methods A retrospective analysis of 299 ERCPs performed by 4 endoscopists over an 18-month period, at a single tertiary care center was conducted. All inpatients/outpatients (121 males, 178 females) undergoing ERCP for any clinical indication from January 2012 to June 2013 in the chosen ERCP suite were included in the study. Various predetermined clinical, procedural and ergonomic factors were obtained via chart review. Univariate analyses identified factors to be included in the multivariate regression model with FT as the dependent variable.

Results Bringing the endoscopy and fluoroscopy screens next to each other was associated with a significantly lesser FT than when the screens were separated further $(-1.4 \mathrm{~min}, P=0.026)$. Other significant factors associated with a prolonged $\mathrm{FT}$ included having a prior ERCP $(+1.4 \mathrm{~min}, P=0.031)$, and more difficult procedures $(+4.2$ min for each level of difficulty, $P<0.001)$. ERCPs performed by high-volume endoscopists used lesser FT vs. low-volume endoscopists $(-1.82, \mathrm{P}=0.015)$.

Conclusions Our study has identified and validated various factors that affect the total fluoroscopy time during ERCP. This is the first study to show that decreasing the distance between the endoscopy and fluoroscopy screens in the ERCP suite significantly reduces the total fluoroscopy time, and therefore radiation exposure to patients and staff involved in the procedure.

\section{Introduction}

Endoscopic retrograde cholangiopancreatography (ERCP) is a common interventional procedure used for more than 40 years in diagnosis and management of pancreaticobiliary pathologies. By using a specialized side-viewing duodenoscope, the procedure involves injection of radio-opaque contrast into the biliary ducts allowing for both visualization of the anatomy and performance of a variety of therapeutic interventions. Relying heavily on the use of real-time fluoroscopy, ERCP has been recognized to carry a radiation risk, not only for patients undergoing the procedure but also for physicians performing it [1,2]. Guidelines have now been developed by the World Gastroenterology Organization (in collaboration with the International Atomic Energy agency, the American Society for Gastrointestinal Endoscopy, as well as the European Society of Digestive
Endoscopy), to ensure that doses of ionizing radiation received by individuals involved in the procedure are as low as reasonably achievable in order to prevent rare but harmful consequences of radiation exposure [3-5]. There is therefore a need to identify modifiable factors that could help reduce total radiation exposure during ERCPs, and allow for overall safer procedures.

In the past, various factors have been shown to affect the total radiation dose received by patients and staff during ERCP. These include: the type of $x$-ray tube used; distance of personnel from the $x$-ray source; and shielding the body using radioprotective shields. In addition, time spent during fluoroscopy has been shown to have a linear relationship to the radiation dose during ERCP [6]. Therefore, limiting fluoroscopy time (FT) seems to be a simple way of reducing radiation exposure during ERCP. 


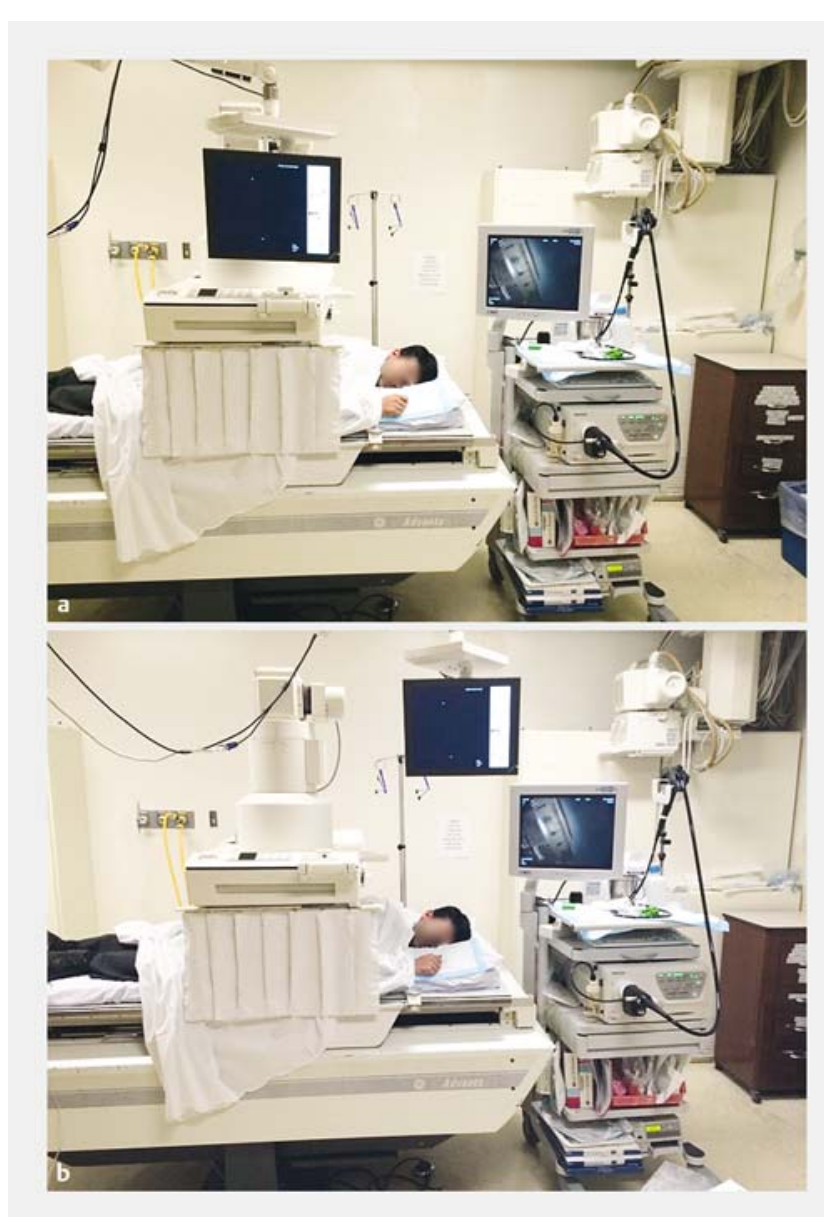

- Fig. 1 a ERCP suite with endoscopy/fluoroscopy screens away (before). b ERCP suite with endoscopy/fluoroscopy screens together (after).

Increased interest in this area has also recently led to benchmarks for FT in ERCP being established in the United States, allowing endoscopists to monitor and improve their own procedure FT over time [7]. In fact, recent recommendations based on currently available evidence and working party expert consensus suggests that endoscopists should record the time and dose of fluoroscopy as part of their documentation for every fluoroscopic session in which they are involved [8]. While some factors affecting FT, such as fluoroscopy equipment used, procedure type, and patient characteristics, are nonmodifiable; identification of potentially modifiable factors would not only allow the endoscopist to predict prolonged fluoroscopy durations but also to possibly undertake relevant precautions accordingly.

Recently, the design of one of our ERCP suites was modified and as a result, the endoscopy and fluoroscopy screens were placed closer together ( $\downarrow$ Fig. $\mathbf{1}$ b) for ergonomic reasons (reducing endoscopists' need to rotate their head and body to view both screens). This provided the opportunity to test whether this specific change would impact the total fluoroscopy time during each ERCP performed. A multivariate analysis was therefore undertaken to investigate these effects, as well as to iden- tify and validate other clinical \& procedural factors associated with prolonged fluoroscopy time (and thus radiation exposure).

\section{Patients and methods}

We performed a retrospective analysis from January 2012 to June 2013 of all ERCPs performed in 1 of 2 ERCP suites at Kingston General Hospital which is a tertiary care center in Kingston, Ontario, Canada. The duration spanned 9 months before to 9 months after the screen move date (September 2012). All inpatients/outpatients undergoing ERCPs in this fluoroscopy suite for any clinical indication were identified using a clinical endoscopy database. After obtaining appropriate ethics approval from our institution's research ethics board, various predetermined clinical, procedural and ergonomic factors as well as fluoroscopy times for each procedure were obtained via thorough chart review ( $\triangleright$ Table 1 ). All procedures performed prior to September 2012 were included in the "screens away" group (endoscopy and fluoroscopy screens located away from each other); while those performed October 2012 onwards were included in the "screens together" group.

Data were entered into an Excel file designed for the study, and imported into IBM SPSS (version 21.0, Armonk, New York, 2012) for statistical analysis. Data were initially analyzed descriptively, and both fluoroscopy time and procedure time were plotted to assess the underlying distribution. Factors associated with lengthened FT were then assessed using independent samples t-tests for 2-level variables, 1-way ANOVAs for categorical variables with more than 2 levels, and correlations for the continuous data. Promising factors from the univariate analysis including our primary study factor (screen position) were then included in the multivariable linear regression analysis with FT as the dependent variable (age, sex, prior ERCP, grade based on difficulty, volume, fellow involvement and screen distance). Variables were then removed sequentially using a backward, manual approach, based on the updated $P$ values at each iteration. Final significance was established at a $P$ value $<0.05$ with factors having $P$ values $<0.05$ affecting the fluoroscopy time significantly.

\section{Results}

A total of 299 ERCPs were performed on 121 males (40.5\%) and 178 females (59.5\%) in the selected ERCP suite in the chosen time frame ( $\triangleright$ Table 1 ) (representing approximately $50 \%$ of the total ERCPs performed). The mean fluoroscopy time was $6.67 \pm 5.75 \mathrm{~min}$; and the mean procedure time was $33.6 \pm$ $18.19 \mathrm{~min}$. Both were reasonably normally distributed, with only a slight skew to the right for fluoroscopy time.

Most procedures were performed for therapeutic (91.3\%) compared to diagnostic reasons (8.7\%). One hundred nineteen patients (39.8\%) had previously had an ERCP, with a previous sphincterotomy in 99 patients (83.2\%). Most procedures were performed in the left semi-prone position (95.3\%). Four endoscopists performed the ERCPs (3 gastroenterologists, 1 general surgeon). A gastroenterology fellow (residents in their fifth or sixth year of post-graduate training in gastroenterology) was 
- Table 1 Patient, clinical and procedural characteristics along with results from the univariate analysis.

\begin{tabular}{|c|c|c|c|}
\hline Variable & No. of ERCPs (\%) & Mean FT \pm SD (min.) & $P$ value \\
\hline \multicolumn{4}{|l|}{ Sex } \\
\hline $\begin{array}{l}\text { - Male } \\
\text { - Female }\end{array}$ & $\begin{array}{l}121(40.5) \\
178(59.5)\end{array}$ & $\begin{array}{l}6.64 \pm 5.50 \\
6.71 \pm 5.93\end{array}$ & 0.901 \\
\hline \multicolumn{4}{|l|}{ Indication } \\
\hline $\begin{array}{l}\text { - Diagnostic } \\
\text { - Therapeutic }\end{array}$ & $\begin{array}{c}26(8.7) \\
273(91.3)\end{array}$ & $\begin{array}{l}5.77 \pm 3.31 \\
6.73 \pm 5.93\end{array}$ & 0.393 \\
\hline \multicolumn{4}{|c|}{ Pre-procedure characteristics } \\
\hline $\begin{array}{l}\text { - Prior ERCP } \\
- \text { Yes } \\
- \text { No }\end{array}$ & $\begin{array}{l}119(39.8) \\
180(60.2)\end{array}$ & $\begin{array}{l}7.78 \pm 7.29 \\
5.97 \pm 4.33\end{array}$ & 0.008 \\
\hline $\begin{array}{l}\text { - Prior sphincterotomy } \\
\text { - Yes } \\
\text { - No }\end{array}$ & $\begin{array}{l}99(33.1) \\
18(6.0)\end{array}$ & $\begin{array}{l}7.95 \pm 7.50 \\
7.33 \pm 7.05\end{array}$ & 0.745 \\
\hline $\begin{array}{l}\text { - Prior stent } \\
\text { - Yes } \\
\text { - No }\end{array}$ & $\begin{array}{r}71(23.7) \\
226(75.6)\end{array}$ & $\begin{array}{l}7.96 \pm 7.73 \\
6.28 \pm 4.95\end{array}$ & 0.032 \\
\hline \multicolumn{4}{|l|}{ Endoscopists } \\
\hline $\begin{array}{l}\text { - Endoscopist } 1 \\
\text { - Endoscopist } 2 \\
\text { - Endoscopist } 3 \\
\text { - Endoscopist } 4\end{array}$ & $\begin{array}{r}163(54.5) \\
60(20.1) \\
37(12.4) \\
39(13)\end{array}$ & $\begin{array}{l}6.30 \pm 5.80 \\
6.92 \pm 4.20 \\
6.67 \pm 5.95 \\
7.95 \pm 7.25\end{array}$ & 0.441 \\
\hline \multicolumn{4}{|l|}{ Volume } \\
\hline $\begin{array}{l}\text { - High } \\
\text { - Low }\end{array}$ & $\begin{array}{r}223(74.6) \\
76(25.4)\end{array}$ & $\begin{array}{l}6.47 \pm 5.417 \\
7.33 \pm 6.636\end{array}$ & 0.261 \\
\hline \multicolumn{4}{|l|}{ Fellow involved } \\
\hline $\begin{array}{l}\text { - Yes } \\
\text { - No }\end{array}$ & $\begin{array}{l}172(57.5) \\
127(42.5)\end{array}$ & $\begin{array}{l}7.26 \pm 6.67 \\
5.92 \pm 4.10\end{array}$ & 0.046 \\
\hline \multicolumn{4}{|l|}{ Patient position } \\
\hline $\begin{array}{l}\text { - Left semi-prone } \\
\text { - Left lateral decubitus }\end{array}$ & $\begin{array}{l}285(95.3) \\
14(4.7)\end{array}$ & $\begin{array}{l}6.66 \pm 5.75 \\
7.17 \pm 6.02\end{array}$ & 0.749 \\
\hline \multicolumn{4}{|l|}{ Instruments used } \\
\hline $\begin{array}{l}\text { - Balloon (extraction) } \\
\text { - Yes } \\
\text { - No }\end{array}$ & $\begin{array}{l}182(60.9) \\
117(39.1)\end{array}$ & $\begin{array}{l}6.93 \pm 5.80 \\
6.23 \pm 5.67\end{array}$ & 0.369 \\
\hline $\begin{array}{l}\text { - Basket } \\
\text { - Yes } \\
\text { - No }\end{array}$ & $\begin{array}{r}33(11) \\
266(89)\end{array}$ & $\begin{array}{r}12.56 \pm 7.92 \\
5.92 \pm 4.98\end{array}$ & $<0.001$ \\
\hline $\begin{array}{l}\text { - Stone-crusher } \\
\text { - Yes } \\
\text { - No }\end{array}$ & $\begin{array}{c}19(6.4) \\
280(93.6)\end{array}$ & $\begin{array}{r}14.97 \pm 9.88 \\
6.09 \pm 4.90\end{array}$ & $<0.001$ \\
\hline $\begin{array}{l}\text { - Dilator (balloon/rigid) } \\
\text { - Yes } \\
\text { - No }\end{array}$ & $\begin{array}{c}28(9.4) \\
271(90.6)\end{array}$ & $\begin{array}{r}10.26 \pm 5.92 \\
6.32 \pm 5.62\end{array}$ & $<0.001$ \\
\hline \multicolumn{4}{|l|}{ Sphincterotomies } \\
\hline $\begin{array}{l}\text { - Yes } \\
\text { - No }\end{array}$ & $\begin{array}{l}167(55.9) \\
132(44.1)\end{array}$ & $\begin{array}{l}6.09 \pm 4.39 \\
7.45 \pm 7.06\end{array}$ & 0.042 \\
\hline
\end{tabular}


- Table 1 (Continuation)

\begin{tabular}{|c|c|c|c|}
\hline Variable & No. of ERCPs (\%) & Mean FT \pm SD (min.) & $P$ value \\
\hline \multicolumn{4}{|l|}{ Stents } \\
\hline $\begin{array}{l}\text { - Inserted? } \\
\text { - Yes } \\
\text { - No }\end{array}$ & $\begin{array}{l}121(40.5) \\
178(59.5)\end{array}$ & $\begin{array}{l}8.26 \pm 6.90 \\
5.57 \pm 4.54\end{array}$ & $<0.001$ \\
\hline $\begin{array}{l}\text { Number } \\
-1 \text { stent } \\
->1 \text { stent }\end{array}$ & $\begin{array}{c}111(91.7) \\
10(8.2)\end{array}$ & $\begin{array}{l}8.13 \pm 7.05 \\
8.37 \pm 5.34\end{array}$ & 0.822 \\
\hline $\begin{array}{l}\text { - Cytology brushings } \\
- \text { Yes } \\
\text { - No }\end{array}$ & $\begin{array}{r}33(11.0) \\
265(88.6)\end{array}$ & $\begin{array}{l}6.83 \pm 3.98 \\
6.66 \pm 5.95\end{array}$ & 0.874 \\
\hline \multicolumn{4}{|l|}{ Stones } \\
\hline $\begin{array}{l}\text { - Present } \\
\text { - Yes } \\
\text { - No }\end{array}$ & $\begin{array}{l}128(42.8) \\
171(57.2)\end{array}$ & $\begin{array}{l}7.84 \pm 6.36 \\
5.62 \pm 4.68\end{array}$ & 0.001 \\
\hline $\begin{array}{l}\text { Total } \\
\text { - } 1 \text { stone } \\
-2 \text { stones } \\
-3 \text { stones } \\
-4 \text { or more }\end{array}$ & $\begin{array}{l}58(45.3) \\
14(10.9) \\
14(10.9) \\
42(32.8)\end{array}$ & $\begin{array}{l}6.59 \pm 6.84 \\
8.34 \pm 5.23 \\
9.15 \pm 6.65 \\
8.96 \pm 5.79\end{array}$ & 0.240 \\
\hline $\begin{array}{l}\text { - Size } \\
\text { - Small } \\
\text { - Moderate } \\
\text { - Large }\end{array}$ & $\begin{array}{l}71(55.5) \\
13(10.2) \\
44(34.4)\end{array}$ & $\begin{array}{r}5.73 \pm 3.93 \\
6.80 \pm 4.03 \\
11.55 \pm 8.25\end{array}$ & $<0.001$ \\
\hline $\begin{array}{l}\text { - Location } \\
\text { - CBD } \\
\text { - Other (including L/R hepatic, common hepatic \& cystic) }\end{array}$ & $\begin{array}{c}117(91.4) \\
11(8.6)\end{array}$ & $\begin{array}{r}7.49 \pm 6.22 \\
11.57 \pm 6.99\end{array}$ & 0.042 \\
\hline $\begin{array}{l}\text { Successfully removed } \\
\text { - Yes } \\
\text { - No }\end{array}$ & $\begin{array}{r}107(83.6) \\
21(16.4)\end{array}$ & $\begin{array}{r}7.00 \pm 5.15 \\
12.14 \pm 9.64\end{array}$ & 0.001 \\
\hline \multicolumn{4}{|l|}{ Adverse event(s) } \\
\hline $\begin{array}{l}\text { - Yes } \\
\text { - No }\end{array}$ & $\begin{array}{c}10(3.3) \\
289(96.7)\end{array}$ & $\begin{array}{l}9.29 \pm 8.04 \\
6.09 \pm 4.97\end{array}$ & $<0.001$ \\
\hline \multicolumn{4}{|l|}{ Grade (based on difficulty) } \\
\hline $\begin{array}{l}\text { - Least difficult (1) } \\
\text { - Moderately difficult (2) } \\
\text { - Most difficult (3) }\end{array}$ & $\begin{array}{c}204(74.7) \\
47(17.2) \\
22(8.1)\end{array}$ & $\begin{array}{r}5.39 \pm 4.34 \\
9.50 \pm 6.14 \\
14.08 \pm 9.65\end{array}$ & $<0.001$ \\
\hline \multicolumn{4}{|l|}{ Screen distance } \\
\hline $\begin{array}{l}\text { - Away } \\
\text { - Close }\end{array}$ & $\begin{array}{l}160(53.5) \\
139(46.5)\end{array}$ & $\begin{array}{l}7.08 \pm 6.58 \\
6.23 \pm 4.60\end{array}$ & 0.194 \\
\hline
\end{tabular}

involved in 172 cases (57.5\%). Most procedures (74.7\%) were considered grade 1 on a validated 3 point scale of difficulty (1: least difficult, 2: moderately difficult, and 3: most difficult) [22]. A total of 160 procedures (53.5\%) had been performed with the screens away from each other, whereas 139 procedures $(46.5 \%)$ had the screens placed next to each other.

A total of 10 cases (3.3\%) encountered some sort of an adverse event (hemodynamic instability or minor to moderate bleeding requiring epinephrine injections, balloon tamponade or clip application). Multiple instruments (including extraction balloons, baskets, stone-crushers, balloon/rigid dilators, snares, needle knives etc.) were identified as having been used in the procedures depending on the cases and the pathologies identified.

In the univariate analysis, a strong positive correlation was found between fluoroscopy time (FT) and procedure time $(r=$ $0.693, P<0.001)$. Mean FT was found to be prolonged in cases with prior ERCPs ( $7.78 \mathrm{~min}, P=0.008)$; fellow involvement ( 7.26 
- Table 2 Results of multivariate analysis.

\begin{tabular}{|c|c|c|c|c|}
\hline \multirow[t]{2}{*}{ Factors } & \multicolumn{2}{|c|}{ Model with selected variables from univariate analysis } & \multicolumn{2}{|l|}{ Final model } \\
\hline & $\beta(95 \% \mathrm{CI})$ & $P$-value & $\beta(95 \% \mathrm{Cl})$ & $P$ value \\
\hline Constant & $1.5(-2.3,5.4)$ & 0.432 & $4.04(1.5,6.6)$ & 0.002 \\
\hline Age & $0.02(-0.01,0.06)$ & 0.180 & & \\
\hline Sex & $0.11(-1.15,1.36)$ & 0.867 & & \\
\hline Prior ERCP & $1.4(0.12,2.68)$ & 0.032 & $1.4(0.12,2.67)$ & 0.031 \\
\hline Grade based on difficulty & $4.2(3.12,5.2)$ & $<0.001$ & $4.2(3.2,5.2)$ & $<0.001$ \\
\hline Volume & $-1.75(-3.2,-0.28)$ & 0.019 & $-1.82(-3.29,-0.36)$ & 0.015 \\
\hline Fellow involved & $1.22(-0.06,2.48)$ & 0.061 & & \\
\hline Screen distance close & $-1.27(-2.54,0.006)$ & 0.051 & $-1.4(-2.64,-0.16)$ & 0.026 \\
\hline
\end{tabular}

$\min , P=0.046)$; use of basket $(12.56 \mathrm{~min}, P<0.001)$, stonecrushers (14.97 min, $P<0.001)$, balloon/rigid dilators $(10.26$ min, $P<0.001)$, stents $(8.26 \mathrm{~min}, P<0.001)$; stones $(7.84 \mathrm{~min}$, $P=0.002)$, and procedures with adverse event(s) $(9.29 \mathrm{~min}, P<$ $0.001)$. Large stones had a significantly greater $F T$ than small or moderate-size stones $[F(2,125=13.879, P<0.001]$.

After controlling for confounding factors and interactions, the multivariable regression analysis demonstrated that placing the endoscopy and fluoroscopy screens next to each other was associated with a significantly lesser FT than when the screens were away $(-1.4 \mathrm{~min}, P=0.026)$. Other significant predictors associated with a prolonged FT included those with prior ERCPs $(+1.4 \mathrm{~min}, P=0.031)$ and the grade of procedural difficulty $(+4.2 \mathrm{~min}$ for each grade of difficulty, $P<0.001)$. Endoscopists performing high-volume endoscopies had shorter fluoroscopy times compared to low-volume endoscopists $(-1.82$ mins, $P=0.015)$ ( $\triangleright$ Table 2$)$.

\section{Discussion}

In our study, various factors were identified as affecting the total fluoroscopy duration (and therefore the total radiation received) during ERCP, validating the results from research in the past. However, based on our multivariate analysis, we also concluded that a simple ergonomic modification in the ERCP suite made by reducing the distance between the endoscopy and fluoroscopy screens, significantly reduces the fluoroscopy time during the procedure. Prior to making these modifications, the endoscopy and fluoroscopy screens in our ERCP suite were located away from each other ( $\triangleright$ Fig. 1 a; distance between the centers of both screens $130 \mathrm{~cm}$ ). As a result, the endoscopists found themselves having to constantly move their heads in order to switch views between the 2 screens, which not only affected overall body positioning but also risked scope positioning. Even though not formally tested in this study, we believe that bringing the screens together ( $\vee$ Fig. $\mathbf{1}$ b; new dis- tance between the centers of both screens $=70 \mathrm{~cm}$ ) narrows the endoscopists' field of vision leading to decreased head/body movements; improved simultaneous visualization of both images; and therefore better stability with the scope. This may therefore allow for more successful procedures, and based on our results, decrease fluoroscopy times and lower radiation risk to both patients and staff involved in the procedure. It may seem obvious to assume that the endoscopy and fluoroscopy screens would be placed next to each other in most endoscopy suites; however, in the absence of any formal recommendations, we found a great deal of variability in the designs of ERCP suites, specifically screen positioning, via an informal survey conducted across many North American institutions.

Currently, there are no formal guidelines on the ergonomics of endoscopy; however, certain recommendations have previously been extrapolated from the laparoscopic surgery and general ergonomics literature to minimize musculoskeletal complaints and overuse injury of endoscopists [9]. Specifically, recommendations to position the endoscopy and fluoroscopy monitors somewhere directly in front of the endoscopist, with monitor height just at or below eye level, as well as having the examination table at or below the elbow height, have been recommended. No recommendations with regards to exact screen positioning have been made and no ergonomic modifications have ever been shown to affect fluoroscopy time in the past. While acknowledging the need for further research in ergonomics in gastrointestinal endoscopy [10], the ASGE (American Society for Gastrointestinal Endoscopy) in their evaluation report highlight that methods to limit patients and staff exposure to fluoroscopy are paramount to maintaining a safe work environment. Bringing the screens right next to each other, and directly in front of the endoscopists' view, would not only reduce fluoroscopy times, but also allow for compliance with previous recommendations. 
Retrospective research in the past has established various factors that directly affect the total radiation dose received by personnel during ERCP and other fluoroscopic procedures. These factors include: the type of x-ray tube used (over-couch C-arm units vs. under-couch units) [11] ; mobile vs. stationary $\mathrm{x}$-rays [12]; distance of personnel from the $\mathrm{x}$-ray source [11, $12]$; use of radio-protective shields to shield the body $[13,14]$; and total time spent in fluoroscopy during the procedure (a collinear relationship)[1]. In addition, fluoroscopy time during ERCP has recently been shown to be affected by several factors including: type of fluoroscopy used (pulsed vs. continuous vs. time limited) [15 - 17]; indication for ERCP (diagnostic vs. therapeutic); physician education and experience [18,19]; altered anatomy; and various procedure-specific factors including stent insertion, lithotripsy, taking biopsies, and use of instruments [20]. Moreover, an observational prospective study from Greece identified multiple clinical factors that were found to prolong total fluoroscopy time during ERCP. These clinical factors included: choledocholithiasis, multiple CBD stones, stone size $>10 \mathrm{~mm}$, needle-knife papillotomy, presence of periampullary diverticulum and mechanical lithotripsy [21]. However, this study was performed by a single endoscopist, which limits the overall generalizability of the findings.

In our cohort of patients, various procedural factors determined the grade of procedural difficulty such as difficult/failed cannulations, failed stone retrieval, difficult stent insertions, patient non-compliance, and distorted anatomy secondary to prior surgeries. As expected, the multivariate analysis found that the grade of procedural difficulty was associated with prolonged fluoroscopy times (FT). Difficulty of procedures was based on the widely used and validated ERCP difficulty grading scale by Cotton et. al. [22]. Grade 3 procedures (most difficult) had the highest fluoroscopy time (an additional 12.6 mins), followed by the moderately difficult grade 2 procedures (additional 8.4 mins of fluoroscopy time). Grade 1 procedures (least difficult) had the lowest fluoroscopy time. Even though grade of difficulty as a predictor of fluoroscopy time, would be considered a non-modifiable factor, anticipating prolonged fluoroscopy times in ERCPs that are going to be technically difficult such as cases involving removal of larger CBD stones, intrahepatic stones, or patients with Billroth II anatomy, would not only allow for a more informed consent about potential radiation risks but would also allow the endoscopist and ERCP personnel to take relevant precautions accordingly.

Using instruments such as baskets, stone-crushers, and balloon/rigid dilators in the common bile duct significantly increased the FT, as did presence of stones. Interestingly having multiple stones did not increase the $\mathrm{FT}$, primarily because most of these stones were small and easily removed with 1 to 2 basket sweeps without adding to the FT. Having a prior sphincterotomy was not associated with longer FTs, most likely due to easier cannulation of the papilla. Patients with prior ERCPs were found to have longer FT than those who were ERCP-naïve, and this maintained significance in the final regression analysis. This was most likely because most ERCPs in these patients were performed for non-functioning stents, requiring removal and reinsertion of newer stents, thereby prolonging both the procedure and FT.

Our study did have some limitations. It was retrospective and performed in an endoscopy suite at a single tertiary center. The volume of ERCPs performed in the chosen endoscopy suite may not have accurately reflected the overall volume of procedures performed at our center. However, the significant decrease in fluoroscopy time/exposure achieved by simply moving the endoscopy and fluoroscopy screens together cannot be ignored. In addition, even though a retrospective study has its drawbacks, we feel that performing this study prospectively may well have modified the endoscopists' behavior and confounding may have occurred due to the Hawthorne effect.

\section{Conclusion}

Recently, there has been a lot of interest generated by research in the field of fluoroscopy duration during ERCP, due to the associated radiation risks to both patients as well as the endoscopy staff involved in the procedure $[8,23]$. While being aware of the clinical factors affecting fluoroscopy time during ERCP such as the presence of stones or having a stricture does hold some merit, these factors are for the most part non-modifiable. Therefore, one needs to search for other means to reduce radiation exposure during ERCP, and a simple ergonomic change by reducing the distance between two screens in the endoscopy suite is an easily achievable alternative. Currently, sample frameworks for endoscopy suite designs are available, yet there is no established standard in that regard in either Canada or the United States. This is the first study to show that decreasing the distance between the fluoroscopy and endoscopy screens in the ERCP suite significantly reduces FT during the procedure.

\section{Competing interests}

None

References

[1] Larkin C, Workman A, Wright R et al. Radiation doses to patients during ERCP. Gastrointest Endosc 2001; 53: 161 - 164

[2] Naidu LS, Singhal S, Preece DE et al. Radiation exposure to personnel performing endoscopic retrograde cholangiopancreatography. Postgrad Med J 2005; 81: 660-662

[3] de Revision E, Uradomo L, Cohen H et al. World Gastroenterology Organization Practice Guideline: Radiation protection in the endoscopy suite-Minimizing radiation exposure for patients and staff in endoscopy: a joint ASGE/IAEA/WGO guideline [Official Spanish translation of the WGO]. Gastroenterologia Latinoamerican 2012; 36: 202

[4] Rehani M, Vano E, Ciraj-Bjelac O et al. Radiation and cataract. Radiat Protection Dosimetry 2011; 147: 300 - 304

[5] Kleinerman RA. Cancer risks following diagnostic and therapeutic radiation exposure in children. Pediatr Radiol 2006; 36: (Suppl. 02): $121-125$

[6] Campbell N, Sparrow K, Fortier M et al. Practical radiation safety and protection for the endoscopist during ERCP. Gastrointest EndosC 2002; 55: 552- 557 
[7] Romagnuolo J, Cotton PB. Recording ERCP fluoroscopy metrics using a multinational quality network: establishing benchmarks and examining time-related improvements. Am J Gastroenterol 2013; 108: $1224-1230$

[8] Ho IK, Cash BD, Cohen $\mathrm{H}$ et al. Radiation exposure in gastroenterology: improving patient and staff protection. Am J Gastroenterol 2014; 109: 1180 - 1194

[9] Shergill AK, McQuaid KR, Rempe ID. Ergonomics and GI endoscopy. Gastrointest. Endosc 2009; 70: 145-153

[10] Pedrosa MC, Farraye FA, Shergill AK et al. Minimizing occupational hazards in endoscopy: personal protective equipment, radiation safety, and ergonomics. Gastrointest Endosc 2010; 72: 227 - 235

[11] Buls N, Pages ], Mana F et al. Patient and staff exposure during ERCP. $\mathrm{Br}$ J Radiol 2002; 75: 435-443

[12] Johlin FC, Pelsang RE, Greenleaf M. Phantom study to determine radiation exposure to medical personnel involved in ERCP fluoroscopy and its reduction through equipment and behavior modifications. Am J Gastroenterol 2002; 97: 893-897

[13] Chen MY, Van swearingen FL, Mitchell R et al. Radiation exposure during ERCP: effect of a protective shield. Gastrointest Endosc 1996; 43: $1-5$

[14] Cohen RV, Aldred MA, Paes WS et al. How safe is ERCP to the endoscopist? Surg Endosc 1997; 11: 615-617
[15] Hernandez RJ, Goodsitt MM. Reduction of radiation dose in pediatric patients using pulsed fluoroscopy. AJR Am J Roentgenol 1996; 167 : $1247-1253$

[16] Scanavacca M, D'avila A, Velarde JL et al. Reduction of radiation exposure time during catheter ablation with the use of pulsed fluoroscopy. Int J Cardiol 1998; 63: 71 - 74

[17] Uradomo LT, Goldberg EM, Darwin PE. Time-limited fluoroscopy to reduce radiation exposure during ERCP: a prospective randomized trial. Gastrointest Endosc 2007; 66: 84 -89

[18] Jorgensen J, Rubenstein ], Goodsitt M et al. Radiation doses to ERCP patients are significantly lower with experienced endoscopists. Gastrointest Endosc 2011; 72: 58-65

[19] Uradomo LT, Lustberg ME, Darwin PE. Effect of physician training on fluoroscopy time during ERCP. Dig Dis Sci 2006; 51: $909-914$

[20] Kim E, Mcloughlin M, Lam EC et al. Prospective analysis of fluoroscopy duration during ERCP: critical determinants. Gastrointest Endosc 2010; 72: $50-57$

[21] Katsinelos P, Gatopoulou A, Gkagkalis S et al. A prospective analysis of factors influencing fluoroscopy time during therapeutic ERCP. Ann Gastroenterol 2012; 25: 338-344

[22] Cotton PB, Eisen G, Romagnuolo J et al. Grading the complexity of endoscopic procedures: results of an ASGE working party. Gastrointest Endosc 2011; 73: 868-874

[23] Adler DG, Lieb JGII, Cohen J et al. Quality indicators for ERCP. Am J Gastroenterol 2015; 110: 91 - 101 